\title{
PO-210 AS A TRACER FOR RADON IN DWELLINGS
}

\section{CHRISTER SAMUELSSON, LENA JOHANSSON AND MARGARETA WOLFF}

Radiation Physics Department, LUND UNIVERSITY

University Hospital, $S 22185$, LUND

Sweden

\section{DISCLAIMER}

\begin{abstract}
This report was prepared as an account of work sponsored by an agency of the United States Government. Neither the United States Government nor any agency thereof, nor any of their employees, makes any warranty, express or implied, or assumes any legal liability or responsibility for the accuracy, completeness, or usefulness of any information, apparatus, product, or process disclosed, or represents that its use would not infringe privately owned rights. Reference herein to any specific commercial product, process, or service by trade name, trademark, manufacturer, or otherwise does not necessarily constitute or imply its endorsement, recommendation, or favoring by the United States Government or any agency thereof. The views and opinions of authors expressed herein do not necessarily state or reflect those of the United States Government or any agency thereof.
\end{abstract}

\section{NRE-V}

Salzburg Austria

September 22-28, 1991 
Let us introduce the field of retrospective radon (Rn-222) monitoring by going back to the early days of radiation history, those exciting days of scientific life when radon and thoron were called "emanation" and radon decay products were called "Aktive Nlederschlag" here in the empire of Austria and "active deposit" in the English-speaking world.

In these early days of radiation history the chart of the nuclides and isotopy were unknown to mankind and physicists were naturally very confused, both by the radiation itself and by the "emanation" and the plate-out phenomena. A quotation from Rutherford is representative "The emanation possesses a very remarkable property ... of producing radio-activity in all substances on which it falls". "The mystery deepened further when it was found that the deposited activity could not be removed. This is what Crookes had to say in 1903: "the persistance of radio-activity on glass vessels which have contained radium is remarkable. Filters, beakers, dishes used in the laboratory for operations with radium, after having been washed in the usual way, remain radio-active;" 2 "

Through these two now rather dated quotations we have actually met the two physical processes that are fundamental to retrospective radon monitoring: 1) plate-out of short-lived radon daughters and 2) ion implantation by alpha recoils. The first process, plate-out, is the necessary "marriage" between the radon decay atom and the macroscopic surface. Sticking to a surface prevents the radon daughter from leaving the indoor environment by ventilation. The second process, a daughter nucleus recoiling into the outermost layer of a surface from an outgoing alpha particle, means that subsequent radioactivity survives the interference of human beings who, sooner or later, will disturb the surface, e.g. by cleaning.

The naturally implanted atoms of radon progenies constitute a memory of past air concentration of short-lived radon daughters. $\mathrm{Pb}-210$ has a long half-life (22 years) and therefore $\mathrm{Pb}-210$ and the ensuing radioisotopes (the long-lived daughters) reflect the radon history several decades back in time. To the radon epidemiologist the measurement of implanted, long-lived daughters is very attractive since the time scales for the build-up of lung cancer risks and $\mathrm{Pb}-210$ activity are assumed to be similar.

Our objective in this talk is to illustrate and discuss the correlation between the surface activity of $\mathrm{Po-} 210$ (the grand-daughter of $\mathrm{Pb}-210$ ) and the assumed radon exposure in dwellings. The conclusion of this presentation will be that, provided certain precautions are taken, the surface activity of Po-210 is a very useful retrospective radon monitor. Future work in the field should be devoted to refinements of the method, development of large-scale detectors, and studies of the correlation between individual lung-cancer risks and indoor surface levels of Po-210.

\section{PROBLEMS AND STRATEGY}

Radon exposure in this talk refers to the time-integrated air concentration in a house and we use this quantity for want of something better. Other quantities more closely related to the individual radon lung cancer probability, e.g. cumulated bronchial dose, may be preferred, but impossible or too difficult to estimate with any reasonable accuracy.

Theoretical calculations indicate that a radon exposure of $1000 \mathrm{~Bq} \mathrm{~m}$ over a period of a year implants only a few $\mathrm{Bq} \mathrm{m} \mathrm{m}^{-2}$ of $\mathrm{Pb}-210$. Almost pure $\beta$-emitters at this level are impossible to detect nondestructively, and the most practical way to reveal radon exposures below $1000 \mathrm{~Bq} \mathrm{y} \mathrm{m}^{-3}$ is by the analysis of the alpha decaying grand-daughter Po-210. When Mother Nature for once provides mankind with an ideally thin alpha source, alpha spectrometry 
is natural choice. By using large-area pulse ionization chambers the counting times can be reduced by one or two orders of magnitude compared with the typical value of one week, neccessary whep employing solld-state alpha detectors. An open-flow ionization chamber ${ }^{3 f}$ can accomodate semi-infinite samples, e.g. large windows.

Due to its avallability, physical and electrical properties, etc sheets of glass are the best suited substrate for the implanted activity, ${ }^{4}$ but as with other surfaces in a house, dirtiness is a problem. The range of the recolling atom is only about $0.01 \mathrm{mg} \mathrm{cm}{ }^{-2}$ (50 nm in glass). ${ }^{15}$ Exposing a greasy glass sheet to radon daughters means that the implanted activity resides at least partly in the grease. Four typical (cleaning) behaviour patterns are examplified in Table 1, but only the wife and the husband behaviours are useful for retrospective radon monitoring.

\begin{tabular}{|l|l|}
\hline Code name & Behaviour pattern \\
\hline Wife & Cleaning regulary or when dirty \\
Husband & No cleaning, never, guaranteed \\
Pensioner & Occasional cleaning, does not remember when \\
Batchelor & No cleaning, except the day before measurement \\
\hline
\end{tabular}

The short-lived activity plating out in a dwelling depends on a number of dose- and non-dose-related parameters and a completely free choice of exposure conditions and type of sample will obscure the relationship between radon exposure and implanted radioactivity, as will become evident from the results presented in the next section.

RADON EXPOSURE AND PO-210 SURFACE ACTIVITY INDOORS

At present we have 128 Po-210 values $\left(B q \mathrm{~m}^{-2}\right)$ on glass sheet samples gathered from different dwellings in our data bank. The complete data set of implanted Po-210 activity (i.e. cleaned glass samples) is displayed in Figure 1. Part of the data is still under evaluation, but it is not likely that the data presented will change significantly during the final stages of the follow-up procedure. The final statistical tests on the data have not been completed and the conclusion below should therefore be considered as preliminary.

The dwellings are mainly single-family houses situated in the southern part of Sweden. In the majority of dwellings a single track-etch film supplied by SSI ${ }^{(6)}$ was exposed during a 2-3 month period in order to estimate the radon concentration. The radon exposure was then assessed as the radon concentration times the number of years of exposure, as given by the house-owner. The square of the correlation boefficient, $r^{2}$, of the total set of data is 0.55 .

The radon exposure is evidently uncertain. We estimate the extrapolation error assigned to the long-term average rador concentration to pe $\pm 40 \%$ ( 1 S.D.), based on data published by Bäverstam and Swedjemark. ${ }^{17}$. The total exposure error is further augmented due to errors in the exposure time estimate. The total relative standard deviation of the Po-210 determination is in the majority of cases less than $\pm 10 \%$.

In order to strenghten the data it lis decided to exclude all objects/measurements meeting one or more of the llowing criterla:

1) Hindow panes; a/The radon exposure may be low due to ventilation or outdoor alr infiltration. b/Curtains, radiatios, temperature gradients may cause excessive variations.

2) Ambiguous exposure time; a/Age of sample given anterview differs from written information in the follow-up questionntre.

3) Inferior measurements; a/All Po-210 measurements taken with one detector showing high nolse and low reproducibility (caused by a malfunctioning 
preamplifier) were rejected.

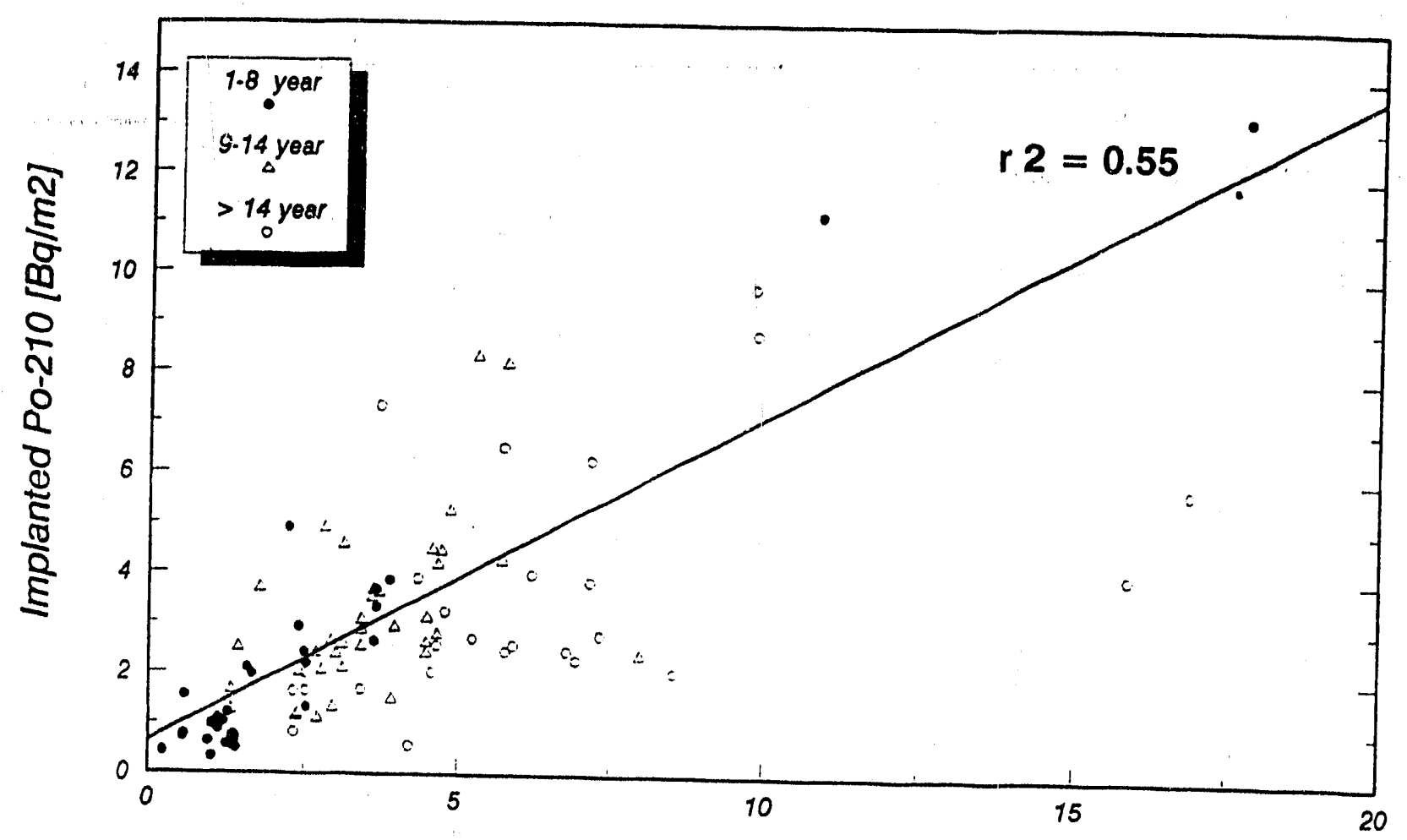

Estimated Radon Exposure [ $\mathrm{kBq}$ y/m3] Fig 1. The Po-210 surface activity of glass samples taken from dwellings. All
types of plane glass included.

All data accepted were divided into the three age groups and are plotted in Figure 2. By deletion of "low-quality" the spread in the data is reduced. Especially the data points for ages below 15 years are well grouped and the correlation is highly positive considering the small range, the uncertainity of the exposure data, and that the cleaning behaviour pattern is unknown.

There is a tendency towards increasing scatter with age in Figure 2. Such a trend is expected since extrapolation errors and the probability of loose contaminants catching the recolls increases with age. It is evident from the cleaning test of household glass samples carried out so far, that the issue of household cleaning behaviour contributes significantly to the increased scatter with age in Figure 2. Particularly the build-up of transparent material (grease, fat etc.) on the glass surface is a problem.

\section{CONCLUSIONS}

Evaluating the glass-polonium method as a retrospective radon monitor in dwellings is not straightforward, as no other comparitive methods are available. Considering these difficulties, the implanted Po-210 activity of indoor vitreous glass correlates well with the estimated radon exposure. The small spread of data for samples younger than 14 years indicates that the inter-house variation of long-term plate-out rates is low, at least much lower than experlenced in some radon-room exercises. Using glass objects that have been kept clean throughout the exposure period and openly exposed to plate-out, will maximize the accuracy of the proposed method. The maximum precision achlevable can not be judged from the data presented here since, unfortunately, the detalled cleaning history is unknown for the majority of
the samples. 


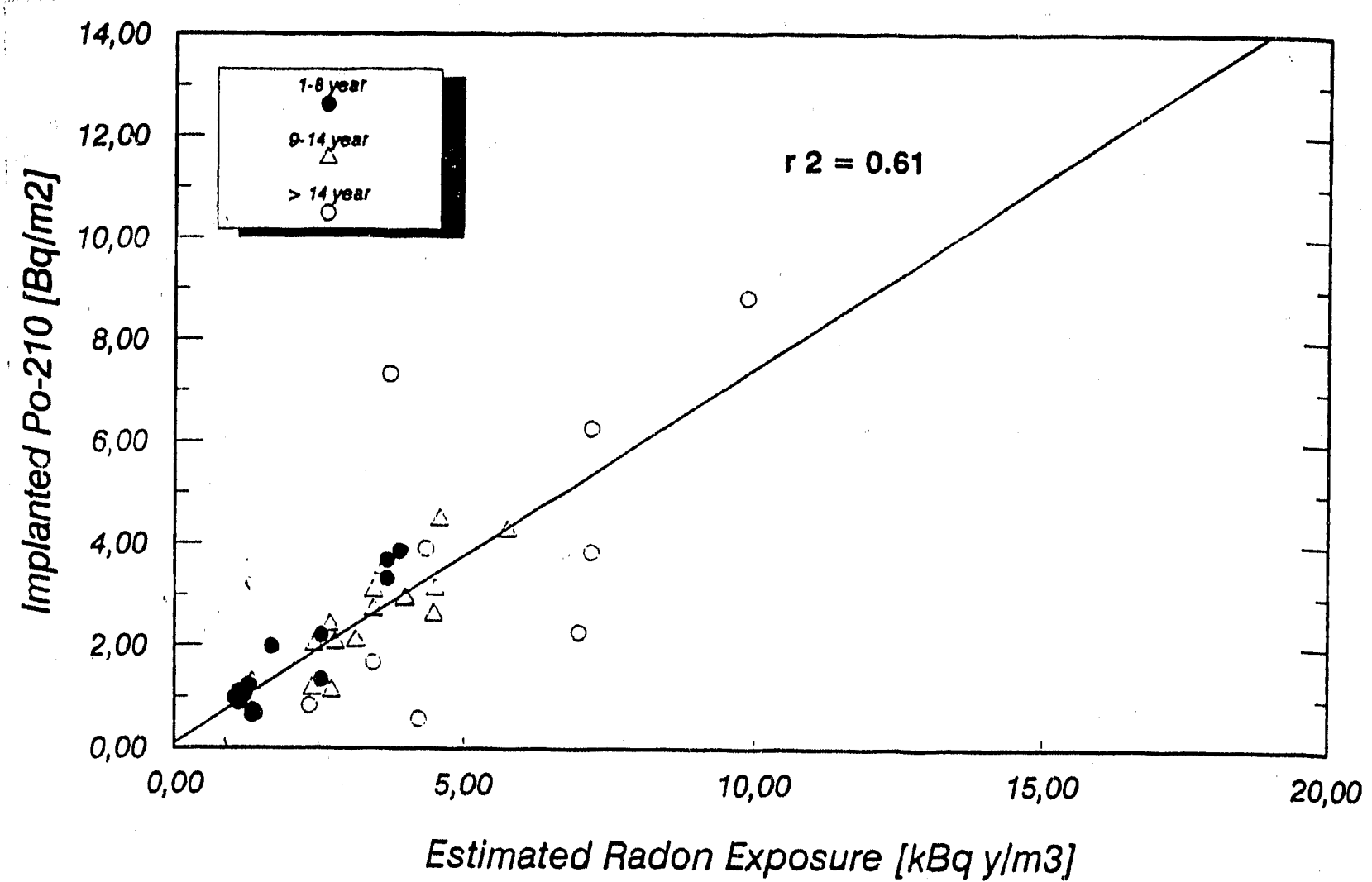

Fig 2. The same as Figure 1, but excluding windows and "low-quality" data (see text). The uncertainity of the radon exposure is around $\pm 40 \%( \pm 1 \mathrm{~S} . \mathrm{D}$.) in most cases.

Acknowledgement

Funding for the radon retrospective program was provided by SSI, Stockholm (grant No. P 505.88), U.S.DOE, Chlcago (grant No. DE-FG02-89ER60911), and CEC, Brussels (contract No. B17*-CT90-0013).

\section{REFERENCES}

${ }^{1} E$. Rutherford "A Radio-active Substance Emitted from Thorium Compounds" Phil. Mag., Ser 5, 49, 1, 1900.

¿W. Crookes "The Emanation of Radium" Proc. Royal Soc. Lond., 71, 404, 1903.

${ }^{3}$ LENA JOHANSSON, B. ROOS \& C. SAMUELSSON "Alpha-Particle Spectrometry of Large-Area Samples Using an Open-Flow Pulse Ionization Chamber" ICRM Symposium 0 Low Level Measuring Techniques and Alpha Particle Spectrometry, Monaco, June 4-7, 1991.

${ }^{4}$ C. SAMUELSSON "Retrospective determination of radon in houses" Nature, No. $6180,334,338,1988$.

${ }^{5}$ C. LANDSHEERE "Experimental and Theoretical Investigation of Po-210 Activity Absorbed in Glass" Nuclear Phys. Lab. , Gent State Univ., Gent, Belgium, 1989. ${ }^{6}$ SSI (National Institute of Radiation Protection), Box 60204, S 10401 Stockholm.

7U. BÄVERSTAM \& G-A SWEDJEMARK "Where Are the Errors when We Estimate Radon Exposure in Retrospect?" Rad. Prot. Dosim., No. 2/4, 36, 107, 1991. 

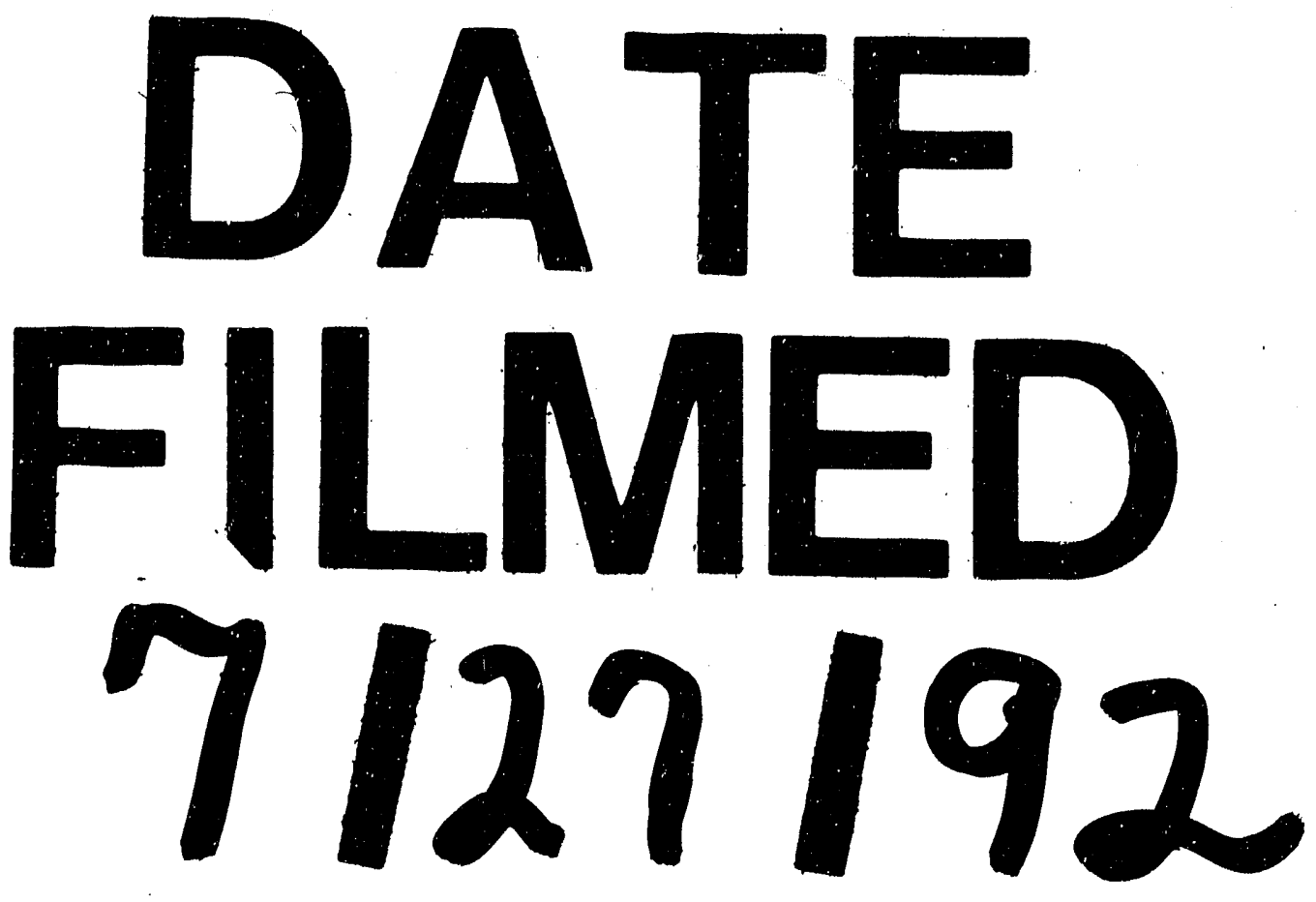
